\title{
RISKS AND DRIVERS OF HYBRID CAR ADOPTION: A CROSS-CULTURAL SEGMENTATION ANALYSIS
}

Fraser McLeay ${ }^{a^{*}}$, Vignesh Yoganathan ${ }^{b}$, Victoria-Sophie Osburg ${ }^{c}$, Ameet Pandit ${ }^{d}$

a Sheffield University, Conduit Rd, Sheffield S10 1FL, UK

b Northumbria University Newcastle, 2 Ellison PI, Newcastle upon Tyne NE1 8ST, UK

c University of Hull, Cottingham Rd, Hull HU6 7RX, UK

d The University of Newcastle, 409 Hunter St, Newcastle NSW 2300, Australia

*Corresponding author. Tel.: +44 (0)7497 800 702, E-Mail address: fraser.mcleay@sheffield.ac.uk

Keywords: cross cultural comparison, cultural dimensions, hybrid cars, new product adoption, risks, environmentally friendly clean products

\section{Abstract}

Throughout the developed world, consumers are increasingly being encouraged to adopt cleaner, more eco-friendly behaviours. However, hybrid car adoption remains low, which impedes the move towards a lower carbon economy. In this paper, we examine the risks and drivers of hybrid car purchases, drawing on consumer behaviour and cultural dimensions theory to account for the heterogeneous, segmented nature of the market. As risk perceptions differ across cultures, and in order to address the lack of cross cultural research on eco-friendly cars, we focus on Australian, South Korean, and Japanese consumers. Based on a survey of 817 respondents we examine how five types of risk (social, psychological, time, financial, and network externalities) and three factors that drive purchasing behaviour (product advantages, product attractiveness, and product superiority) influence consumers perceptions of hybrid cars. Four segments of consumers are identified (pessimists, realists, optimists, and casualists) that also vary according to their environmental selfimage, and underlying cultural values. Our results extend theory by incorporating self-image and cultural dimension theories into a multi-country analysis of the risks and drivers of hybrid car adoption. Our findings have practical implications in terms of marketing strategies and potential policy interventions aimed at mitigating risk perceptions and promoting the factors that drive hybrid car adoption.

(C) 2018. This manuscript version is made available under the CC-BY-NC-ND 4.0 license http://creativecommons.org/licenses/by-nc-nd/4.0/ 


\subsection{INTRODUCTION}

In many parts of the world, governments and policy makers are setting legally binding targets for reducing carbon dioxide emissions and encouraging consumers to transition to more eco-friendly vehicles (Barbarossa et al., 2015; Jansson et al., 2017; Morton et al., 2016). Some countries such as Great Britain, Germany and France are even making plans to ban the sale of new diesel or petrol cars by 2040 (Dorn, 2017; Sylvers \& Stoll, 2017). As we further develop our sustainability agenda, alternative fuel vehicles including plug in electric vehicles (PEVs ${ }^{1}$ ) and hybrid electric vehicles (HEVs) can play an important role in the move towards decarbonising the transportation sector, as they possess technology which can reduce greenhouse gases and pollution (Brand et al., 2017; Wang et al., 2016). However, uptake has been lower than planned, which may have adverse effects on the move to a lower carbon economy (Adnan et al., 2017; Morton et al., 2016). High initial purchase prices (Carley et al., 2016), reduced driving ranges or distances (Axsen et al., 2015) and other factors, mean that many consumers are averse to adopting this new technology (Brand et al., 2017). Policy makers and manufacturers are making efforts to encourage the adoption of clean eco-friendly cars through policy incentives, marketing communications, and new product development (Bakar \& Hasan-Basri, 2017; He et al., 2017; Yang et al., 2017).

The broader literature on sustainability, technology and innovation has shown how socio-technical transitions such as the shift to water pipes, to sewers and from carriages to car, involved a set of processes and social paradigm shifts. These shifts have been driven by factors such as learning, cost dynamics, expectations and uncertainty or risks of a transition towards sustainability (Markard et al., 2012). The sustainability transition arena offers significant potential for further research and an appreciation of different actors including consumer adopters (Falcone, 2014). In the context of the

\footnotetext{
${ }^{1}$ Abbreviations used in this paper include: FRSK (Financial risk); HEV (Hybrid electric vehicles); IDV (Individualism); LTO (Long term orientation); MAS (Masculinity); NRSK (Network externality risk); PADV (Product advantage); PATTR (Product attractiveness); PDI (Power distance index); PEV (Plug in electric vehicles); PSUP (Product superiority); PSYRSK (Psychological risk); SIMG (Environmental self-image); SRSK (Social risk); TRSK (Time risk) and UA (Uncertainty avoidance).
} 
sustainability transition for HEVs, understanding of demand for HEVs is critical for designing more effective adoption policies (Sheldon et al., 2017). These efforts will be enhanced by better grasp of the consumer decision-making process, including the factors that may increase acceptance (Axsen et al., 2015; Barbarossa et al., 2015; Mortan et al., 2016) and the perceived risks that may limit uptake (Doorn \& Verhoef, 2015; Hüttel et al., 2018). In this paper, we provide new insights on the risks and drivers of hybrid car purchases by taking an interdisciplinary approach that draws from consumer behaviour and cultural dimensions theory, and incorporates the heterogeneous, segmented nature of consumers across geo-political borders.

The growing body of literature studying eco-friendly low carbon vehicles has mainly concentrated on PEVs including plug in hybrids that can be powered by gasoline or grid electric as well as "pure" electric vehicles that use grid electricity only (see Adnan et al., 2017 for a recent literature review). Our focus is on HEVs, which are gasoline or diesel fuelled automobiles that use a high-powered battery and electric motor to improve energy efficiency (Axsen \& Kurani, 2013). Unlike PEVs which are powered a combination of electricity and gasoline or solely by electricity, HEVs do not require plugging into an electric grid for refuelling. As such, HEVs may provide solutions to many factors that act as barriers to adopting PEVs including a lack of public electrical charging points (Pierre et al., 2011), range anxiety (Dong et al., 2014) and poor battery life with high replacement costs (Axsen \& Kurani, 2013). Therefore, HEVs may be more practical to adopt than PEVs (Wang et al., 2016). PEVs and HEVs are considerably different from traditional cars due to their innovative technological features and novelty (Adnan et al., 2017; Cherubini et al., 2015). As they are high involvement products, there are considerable levels of financial, psychological and other risks associated with purchasing eco-friendly cars (Barbarossa et al., 2015; Petschnig et al., 2014). A better understanding of both, the risks and drivers associated with purchasing hybrid cars, is crucial to increasing HEV adoption. Therefore, the current study addresses an important gap in the literature and answers calls for more research on high involvement eco-friendly cars made by Barbarossa et al. (2015) and 
Oliver and Lee (2010). Our findings will assist policy makers, marketers and others seeking to induce transitions to a low carbon economy, through the use of low emission vehicles as they would benefit by better understanding consumer decision making.

Extant research has largely ignored the segmented, heterogeneous characteristics of the electric car market (Brand et al., 2017). Although consumer tastes and preferences for new vehicle technology, which may offer a combination of private, symbolic and pro-societal benefits vary, there is a lack of research focusing on the diversity in consumer motivations regarding alternative fuel cars (Axsen et al., 2015). Social barriers and cultural values, which influence the adoption of sustainable consumption, and particularly high involvement, technology rich products, such as eco-friendly cars (Oliver \& Lee, 2010), vary from country to country (Spencer et al., 2015; Wang et al., 2016). Risk perceptions differ across cultures (Park \& Jun, 2003; Kaptan et al., 2013). However, with exceptions (e.g. Barbarossa et al., 2015; Oliver \& Lee, 2010), the majority of consumer research on hybrid car adoption has focussed on consumers from a single country such as China (Wang et al., 2016), USA (Axsen \& Kurani, 2013) and Japan (Iwata \& Matsumoto, 2016). Scholars have investigated crosscultural perceived risks in different purchasing domains such as online shopping (Park \& Jun, 2003; Weber \& Hsee, 1998); e-commerce transactions (Kim et al., 2016) and mobile banking (Mortimer et al., 2015). However, risk has not been examined in a high involvement context. Oliver and Lee (2010) explored how social factors and cultural orientation influence purchase intentions for hybrid car in the USA and Korea, however did not specifically focus on perceived risks. Thus, there is a need for more cross-cultural research that explores the factors that influence sustainable consumption and the adoption of HEVs (Spencer et al., 2015; Wang et al. 2016). In this study we contribute to existing knowledge by exploring risks and drivers in three different countries (Japan, Korea and Australia) where cultural and social values differ.

In summary, the present study addresses gaps in existing knowledge and the issues discussed in the previous paragraphs by presenting the following questions: 1 . what are the perceived risks associated 
with adopting hybrid cars? 2. what are the factors that drive hybrid car purchasing decisions? 3. which potential segments of potential hybrid car buyers exist, based on these risks and drivers? and 4 . how does cultural dimensions theory play a role in influencing purchasing decisions?

The remainder of this paper is structured as follows. In the following sections, the literature which has examined the perceived risks and drivers associated with adopting eco-friendly vehicles is critically reviewed. Next, in the methods section, details of the development of a questionnaire and scales used for an online survey of potential hybrid car buyers in 3 countries are provided. An overview of principal components analysis, which was used to identify the underlying structure of interrelationships between different types of risk and factors that drive purchasing behaviour, as well as cluster analysis, which was employed to identify different segments or taxonomies of consumers, is given. In section 5, the results are presented and discussed, while a conclusion and implications are developed in section 6, which also highlights implications and areas for further research.

\subsection{THE PERCEIVED RISKS ASSOCIATED WITH ADOPTING ECO-FRIENDLY VEHICLES}

HEVs are innovative, novel, high involvement products that utilise the latest advancements in technology (Adnan et al., 2017; Cherubini et al., 2015). The process of adopting or purchasing novel products involves perceived risk associated with the 'subjective expectations of loss' (Stone \& Grønhaug, 1993), and elements of uncertainty (Laukkanen et al., 2009; Petschnig et al., 2014). As the perceived risk associated with adopting such products increase, consumers' motivations to buy or use such products are reduced (Meuter et al., 2005). Perceived risks therefore have substantial impacts on the adoption decisions for high involvement, eco-friendly, innovations such as hybrid cars (Jansson et al., 2011; Petschnig et al., 2014). Therefore, further research into this area is warranted. 
From a consumer behaviour perspective, the perceived risk associated with new products is a multidimensional concept comprised of; financial, social, time, psychological, performance and physical risks (Hirunyawipada \& Paswan, 2006; Stone \& Grønhaug, 1993). In this study, we focus on the first four of these dimensions, but not performance or physical risk. Physical risk relates to health concerns (Jansson et al., 2011) which have been proven to be non-significant in a recent study of alternative fuel vehicle adoption (Petschnig et al., 2014) and therefore was not a focus of this study. As previous studies have indicated the perceived high levels of performance can drive the acceptance of eco-friendly vehicles (Sang \& Bekhet, 2015), we include performance as a driver rather than a risk. We add network externalities risk, which is particularly relevant for innovative high-tech products (Hirunyawipada \& Paswan, 2006) such as hybrid cars, where external networks may significantly influence purchase intention (Anable et al., 2016; Axsen et al., 2015). Each dimension is discussed in detail in the paragraphs that follow.

Financial risk relates to the potential negative financial outcomes which are associated with new product adoption (Stone \& Grønhaug, 1993). Although the owners of hybrid cars (particular plug in vehicles) may gain financial benefits from policy-related remunerations and lower fuel costs (Gallagher \& Muehlegger, 2011; Ozaki \& Sevastyanova, 2011), users face expensive initial purchase prices and high maintenance costs for batteries (Soon et al., 2013), which may impede adoption. To the best of our knowledge the role that financial risk can play in influencing purchasing intentions for high involvement, eco-friendly cars has not been explored.

Social risk refers to the negative consequences associated with unfavorable opinions of significant other people on account of the purchase and use of a product (Dholakia, 2001). Thus, this type of risk, which is associated with symbolic and affective emotions, is particularly crucial for socially conspicuous products such as cars (Steg, 2005). A recent study of UK consumers concluded that symbolic and emotional factors including; social status, an ability to express oneself and what others think of you, have a signficant influence on consumers' attitudes to electric cars (Morton et al., 2016). The results of another study identifed a small segment of consumers that are image concious 
and would never like to be seen in a PEV or associate with the type of people that use PEVs (Anable et al., 2016). Additional research has concluded that social values and norms accompanying the opinions of reference groups had a significant influence on intentions to purchase electric or hybrid cars in both the USA and Korea, (Oliver \& Lee, 2010), China (Wang et al., 2016), and Sweden (Jansson et al., 2017).

Psychological risk can be defined as anxiety and/or uncomfortable feelings arising from anticipated post-behavioural emotions such as worry and tension (Dholakia, 2001; Hirunyawipada \& Paswan, 2006), and can have a major influence on the adoption of HEVs (Wang et al., 2013). Although prior studies have already explored the hedonic attributes (i.e. positive emotions) associated with driving hybrid electric vehicles (e.g. Moons \& De Pelsmacker, 2012; Schuitema et al., 2013), the negative influence of consumers' emotions on hybrid or electric vehicle adoption have not been fully explored (Adnan et al., 2017). As emotions can be a strong determinant of consumer behaviour in highinvolvement situations (Moons \& De Pelsmacker, 2012), psychological risk is likely to influence the adoption of eco-friendly cars (Barbarossa et al., 2015).

Time risk relates to the perception that the adoption and use of an innovative product will take too long (Forsythe et al., 2006), will be a perceived waste of time (McGuire et al., 2010) and may be associated with the loss of time (Roselius, 1971). Buying a a high-involvement car is likely to require consumers to take a considerable time to evaluate the product's attributes and performance (Shukor et al., 2015). Knowledge and experience of eco-friendly cars has been shown to positively influence potential adoption (Adnan et al., 2017), but takes time to develop. An ability to fix or repair rudimentary problems that may occur, and knowledge of how the car works at a mechanical level can influence adoption decisions (Pierre et al., 2011) and take time to develop. Therefore, time risk may be associated with purchasing and operating a hybrid vehicle.

Network externality risk involves consumers' evaluations of the extent to which others in their network also adopt a new product (Hirunyawipada \& Paswan, 2006). Network externalities influence 
consumers' use of technology (Pae \& Hyun, 2002). According to the theory of diffusion of innovations (Rogers, 2010), most consumers' decisions to new product adoption strongly depend on the other consumers' new product adoption decisions (Heidenreich et al., 2017; Rogers, 2010). Studies focusing on the adoption of PIVs and hybrid cars have highlighted the role that hype cycles can play in influencing adoption (Jun, 2012) and how early adopters can stimulate market growth (e.g. Anable et al., 2016; Axsen et al., 2015). However, many market segments are unlikely to adopt new eco-friendly vehicle technology until a certain critical mass is achieved in the market (Brand et al., 2017). Thus, as early adopters of innovative new products, hybrid car buyers may face perceived risks associated with network externalities.

\subsection{DRIVERS OF ADOPTING ECO-FRIENDLY VEHICLES}

Current research also points to a range of factors that drive eco-innovative buying decisions, including hybrid car purchases (e.g., Axsen et al., 2015; Barbarossa et al., 2015; Heidenreich et al., 2017). Drivers of eco-innovative purchases can generally be divided into consumers' perceived product features and consumer characteristics. While consumers' perceptions of eco-innovations originate from different factors such as product attractiveness (Boyd \& Mason, 1999), product advantage (Nakata et al., 2006), and product superiority (Lee \& O'Connor, 2003), consumer characteristics comprise of other dimensions such as an individual's self-image (Sirgy, 1986), cultural dimensions (Hofstede, 2001), and socio-demographic characteristics (Sang \& Bekhet, 2015). In the following two subsections, we further discuss consumers' perceptions of product features (e.g. product attractiveness and advantage) and consumer characteristics such as environmental selfimage and cultural dimensions. A summary overview of all of the perceived drivers and risks is presented in Table 1. 
Table 1: Overview of perceived risks and drivers of hybrid car adoption

\begin{tabular}{|c|c|c|c|c|}
\hline \multicolumn{5}{|c|}{ Perceived risks } \\
\hline Financial risks & Social risks & Time risks & Psychological risks & Network externality risks \\
\hline $\begin{array}{l}\text { - High initial purchase } \\
\text { prices } \\
\text { - High maintenance costs } \\
\text { - Overall financial risk } \\
\text { - Concerns consumer may } \\
\text { not get value for money }\end{array}$ & $\begin{array}{l}\text { - Unfavourable opinions } \\
\text { of other people } \\
\text { - Symbolic and affective } \\
\text { emotions } \\
\text { - Influence on social } \\
\text { - Itatus } \\
\text { - Influence on self-image }\end{array}$ & $\begin{array}{l}\text { - Time for adoption } \\
\text { (understanding product } \\
\text { attributes and features) } \\
\text { - Time for utilisation } \\
\text { - Time for knowledge } \\
\text { development and } \\
\text { understanding how the } \\
\text { product functions }\end{array}$ & $\begin{array}{l}\text { - Anxiety } \\
\text { - Uncomfortable feelings } \\
\text { (worry/tension) } \\
\text { - Cognitive dissonance }\end{array}$ & $\begin{array}{l}\text { - Low likelihood of other } \\
\text { consumers' product } \\
\text { adoption } \\
\text { - Lack of critical mass }\end{array}$ \\
\hline \multicolumn{5}{|c|}{ Perceived drivers } \\
\hline Product attractiveness & Product advantage & Product superiority & Consumer characteristics & \\
\hline $\begin{array}{l}\text { - Values (social, } \\
\text { functional, economic, } \\
\text { hedonic) } \\
\text { - Interpersonal influence } \\
\text { - Aesthetic features } \\
\text { - Convenience } \\
\text { - Financial benefits and } \\
\text { - other incentives } \\
\text { - Improvements over } \\
\text { existing products }\end{array}$ & $\begin{array}{l}\text { - Eco-friendliness } \\
\text { - Energy efficiency } \\
\text { - Cost minimisation } \\
\text { - Improved driving } \\
\text { - } \text { experience } \\
\text { Technological } \\
\text { - Innancements }\end{array}$ & $\begin{array}{l}\text { - New technological } \\
\text { benefits. } \\
\text { - Has introduced new } \\
\text { features to the market } \\
\text { e.g. reduced } \\
\text { dependency on foreign } \\
\text { oil and fuel prices } \\
\text { - Positioning as } \\
\text { technological } \\
\text { trendsetters }\end{array}$ & $\begin{array}{l}\text { - Environmental self- } \\
\text { image } \\
\text { - Cultural dimensions: } \\
\text { long term orientation, } \\
\text { collectivism, femininity, } \\
\text { low uncertainty } \\
\text { avoidance } \\
\text { - Socio-demographic } \\
\text { characteristics: low age, } \\
\text { high income, high } \\
\text { educational level }\end{array}$ & \\
\hline
\end{tabular}




\subsection{Consumers' perception of product features}

Product attractiveness refers to an overall evaluation of a new product, independent of the brand (Boyd \& Mason, 1999). Previous research indicates that consumers' overall assessment of hybrid cars depends on the fulfilment of social (e.g. being proud of the vehicle), functional (e.g. getting a good mileage), economic (e.g. saving money in the long run), and hedonic values (e.g. perceiving the vehicle as exciting) (Hur et al., 2013). The interpersonal influence on buying decisions needs to be considered as consumers show a stronger preference for hybrid cars if they think that such a purchase is supported by relevant other people (Petschnig et al., 2014; Sang \& Bekhet, 2015). Aesthetic features of hybrid cars affect product attractiveness because car purchases are often associated with a buyer's social status (Graham-Rowe et al., 2012; Petschnig et al., 2014). Other product attractiveness factors that influence consumers' adoption of hybrid cars include: convenience (Al-Alawi \& Bradley, 2013; Graham-Rowe et al., 2012), financial benefits such as tax reductions and exemptions (Hackbarth \& Madlener, 2013; Ozaki \& Sevastyanova, 2011), and incentives such as free parking (Hackbarth \& Madlener, 2013). These incentives only promote adoption, if consumers do not have low-quality perceptions of hybrid cars (Heutel \& Muehlegger, 2015), which highlights the importance of a detailed overall evaluation of product attractiveness.

Product advantage describes a comparison with product alternatives, and helps to identify why consumers prefer a new product over existing alternatives (Nakata et al., 2006). Hybrid cars offer several characteristics, which consumers may perceive as advantageous compared with conventional vehicles (Petschnig et al., 2014). For example, the eco-friendliness and energy efficiency of hybrid cars (Adnan et al., 2017), cost minimisation in the long run through reduced fuel costs (Axsen et al., 2015; Sang \& Bekhet, 2015), and several elements of an improved driving experience such as less noise, greater driving comfort, and a better handling (Ozaki \& Sevastyanova, 2011; Schuitema et al., 2013). However, given the technologically-advanced nature of hybrid cars 
(Al-Alawi \& Bradley, 2013) purchase decisions are often predicated upon buyers having a basic understanding of the technology and its advantages (Erdem et al., 2010).

Product superiority is related to the innovativeness of a new product, represented by product features, which consumers perceive as truly novel (Lee \& O'Connor, 2003). It is important that consumers acknowledge innovative characteristics to realize hybrid car adoption (Heidenreich et al., 2017). These can be new technological features such as charging at home (Graham-Rowe et al., 2012), or the focus on electricity rather than gasoline (Carley et al., 2013), resulting in a reduced dependency on foreign oil (Carley et al., 2013) as well as rising fuel prices (Sangkapichai \& Saphores, 2009). This allows hybrid car owners to position themselves not only as green but also as technological trendsetters (Ozaki \& Sevastyanova, 2011).

\subsection{Consumer characteristics}

Existing research recognises the importance of an individual's self-image across various forms of environmental consumption (e.g. Read et al., 2013; Webb et al., 2014). According to self-image congruency theory (Sirgy, 1986), consumers tend to buy products with an image consistent to their self-image/identity. Consequently, if an individual perceives himself/herself as an environmentallyresponsible person, they are more likely to buy an eco-friendly product. An individual's self-image can induce eco-friendly consumption across a range of situations (Barbarossa et al., 2015), including hybrid car purchases (Axsen et al., 2015; Hackbarth \& Madlener, 2013; Sang \& Bekhet, 2015). Furthermore, these adopters tend to be environmentally concerned and express their self-image through the purchase of hybrid cars (Barbarossa et al., 2015; Schuitema et al., 2013). Cross-cultural research has shown that consumers buy hybrid cars more likely if they assume a positive influence on their self-image (Oliver \& Lee, 2010).

Furthermore, cultural dimensions influence eco-friendly purchases such as hybrid car adoption (Barbarossa et al., 2015). Hofstede (2001) describes five dimensions in which cultures differ. The power distance index (PDI) reflects to what extent less powerful individuals agree upon an unequal 
distribution of power within their society. Individualism versus collectivism (IDV) considers whether individuals mainly define themselves as "I" opposed to "We". Masculinity versus femininity (MAS) focuses on achievement and material rewards in contrast to a more cooperative society, which emphasizes personal care. Uncertainty avoidance (UA) describes to what extent members of a society tolerate uncertainty and ambiguity, and are therefore sceptical about new beliefs and behaviours. Finally, long term versus short term normative orientation (LTO) represents a culture's focus on future rewards opposed to past and present benefits. The cultural dimensions may affect hybrid car purchases, as they influence consumers' acceptance of the outlined product characteristics. For instance, previous research has shown that an individual's LTO is associated with environmentally responsible consumption (Urien \& Kilbourne, 2011), and that LTO increases ecofriendly consumption (Dwyer et al., 2005). In contrast, UA and IDV negatively affect eco-friendly purchasing (Kim \& Choi, 2005). Collectivism is measured as a person-level construct and is related to a higher perceived consumer effectiveness, which in turn induces eco-friendly consumption (Kim \& Choi, 2005). Previous research also suggests a potential influence of MAS, since sustainable consumption is perceived as more appropriate for gentleness-related products (attributes such as safety, health; i.e. similar to femininity) compared to strength-related products (e.g. power, durability; i.e. similar to masculinity) (Luchs et al., 2010). LTO, UA, IDV, and MAS are therefore relevant dimensions for eco-friendly purchases such as hybrid cars. Furthermore, UA seems to be particularly crucial as hybrid cars are an innovative (i.e. unknown) product.

Finally, extensive research has pointed to the influence of socio-demographic characteristics on ecofriendly consumption, although their explanatory power appears low (Diamantopoulos et al., 2003). In the context of hybrid car purchases, it has been shown that adopters tend to be rather young (Hackbarth \& Madlener, 2013), have a higher income (Erdem et al., 2010; Sang \& Bekhet, 2015), and higher educational level compared to non-adopters (Hackbarth \& Madlener, 2013; Sang \& Bekhet, 2015). 


\subsection{METHOD AND MEASURES}

\subsection{Participants}

A total of 817 consumers aged over 18 , who currently owned cars and lived in Australia, South Korea and Japan were recruited using a financial incentive to participate in an online questionnaire through a reputable commercial marketing agency (Research Now). A quota sampling method was used to gather a comparable number of responses from each of the three countries, which were representative of car drivers in terms of age and gender profiles. A screening question ensured that all participants were currently car drivers. The data was collected in approximately two weeks.

The online survey started with a description of a typical hybrid car to help ensure participants could evaluate the questions to the best of their ability, and therefore produce usage-based judgments. Australia, South Korea and Japan where targeted as all countries manufactured hybrid cars. In addition, the adoption of hybrid cars in Australia has substantially increased as they are very efficient to run in stop-start traffic (Dowling, 2017).

\subsection{Measures}

A questionnaire was designed to measure the five types of risk that may act as barriers to purchasing hybrid cars, three perceived product features that may act as drivers, and six consumer characteristics and cultural dimensions. In addition, socio-demographic characteristics were also measured. Social Risk (SRSK) was operationalised using three items. Psychological Risk (PSYRSK) included three items while Time Risk (TRSK) was measured using a four-item scale; all adopted from Stone and Grønhaug (1993). To measure Financial Risk (FRSK), we used a two-item scale originally developed by Stone and Grønhaug (1993) that has been used by other scholars (e.g. Ayadi \& Lapeyre, 2016). Network Externality Risk (NRSK) was measured using three items (Hirunyawipada \& Paswan, 2006). Product Advantage (PADV) was measured using five items (Nakata et al., 2006) while product attractiveness (PATTR) was measured using seven items (Boyd \& Mason, 1999). Product Superiority (PSUP) was operationalised using four items (Lee \& O'Connor, 2003). Environmental Self- 
image was adapted from Smith and Paladino (2010) and Paladino and Pandit (2012), using three items. Further, the study included 45 items to measure the five types of value-dimensions based on the seminal work by Hofstede (2001): Masculinity (MAS), Uncertainty Avoidance (UA), Long Term Orientation (LTO), Individualism (IND), and Power Distance (PDI). For all questions, participants were asked to rate on a 7-point Likert scale how much they agreed or disagreed with various statements in the questionnaire (i.e. 1 = very strongly disagree to 7 = very strongly agree). Additional questions asked participants to provide details of their age, income and other socio-demographic information. The original version of the questionnaire was developed in English, and then translated into South Korean and Japanese by a professional translator as per the standards followed by previous researchers (e.g. Sullman et al., 2017). Back translation using the procedure of Hohl and Gaskell (2008) was applied to ensure consistency of meaning. Further, focus groups were conducted in each country to check if all participants clearly understood and could answer each question. In addition, the first draft of the questionnaire was pilot tested with 30 respondents in each of the three countries to ensure that the survey has face and content validity.

The data analysis strategy was predominantly aimed at uncovering and understanding underlying structures in the data, which would allow for the examination of global patterns in hybrid car purchase decisions irrespective of geo-demographic differences. Hence, the application of a dimension reduction technique (Principal Component Analysis) followed by a two-stage cluster analysis was adopted following the precedence set by previous research into environmentally friendly purchase decisions (see: Osburg et al., 2016). However, for a more meaningful definition and development of clusters, we also conducted a set of association and correlation-based tests.

\subsection{Descriptive statistics}

There were 817 usable responses with a mode age-category of 25-34 and approximately equal number of males and females. More than half of the respondents (54.3\%) were university educated. A summary of descriptive statistics is presented in Table 2. 
Table 2 Summary of descriptive statistics

\begin{tabular}{l|l|c|c}
\hline Variable & Category & $\mathbf{n}$ & $\%$ \\
\hline Country & AUS & 255 & 31.2 \\
& SK & 251 & 30.7 \\
& JPN & 311 & 38.1 \\
\hline Gender & Male & 405 & 49.6 \\
& Female & 412 & 50.4 \\
\hline Age & $18-24$ & 48 & 5.9 \\
& $25-34$ & 217 & 26.6 \\
& $35-44$ & 188 & 23 \\
& $45-54$ & 131 & 16 \\
& $55-64$ & 154 & 18.8 \\
& $66+$ & 79 & 9.7 \\
\hline Income & $<\$ 21,000$ & 100 & 12.2 \\
(\$AUS) & $\$ 21,000$ to $\$ 40,999$ & 170 & 20.8 \\
& $\$ 41,000$ to $\$ 60,999$ & 169 & 20.7 \\
& $\$ 61,000$ to $\$ 80,999$ & 132 & 16.2 \\
& $\$ 81,000$ to $\$ 99,999$ & 122 & 14.9 \\
& $>\$ 100,000$ & 124 & 15.2 \\
\hline Education & High School or below & 252 & 30.8 \\
& Diploma/Certificate or equivalent & 122 & 14.9 \\
& Bachelor's Degree or equivalent & 360 & 44.1 \\
& Postgraduate Degree or equivalent & 83 & 10.2 \\
\hline
\end{tabular}

\section{RESULTS}

\subsection{Data analysis}

Following the approach of previous researchers in this field (e.g. Osburg et al., 2016; Vigre et al., 2016), we aimed to identify the underlying structure of interrelationships between the five types of risk and the three factors that drive purchasing behaviour, before proceeding with cluster analysis to identify consumer taxonomies. We obtained composite factor scores for all the multi-item constructs via imputation using the Regression Method. Subsequently, Social Risk (SRSK), Time Risk (TRSK), Psychological Risk (PSYRSK), Financial Risk (FRSK), Network Externality Risk (NRSK), Product Attractiveness (PATTR), Product Superiority (PSUP), and Product Advantage (PADV) items were subjected to a Principal Component Analysis (PCA) with orthogonal rotation (Varimax). 
As summarised in Table 3, two principal components were obtained with Eigenvalues $>1$, and $83.4 \%$ of the total variance explained (all loadings $>0.7 ; \mathrm{KMO}>0.7$; Bartlett's test significant at $1 \%$ level). Results clearly indicate that all five risk-related factors (PSYRSK, FRSK, SRSK, TRSK, and NRSK) load on Component 1, whilst PATTR, PSUP, and PADV load on Component 2. Internal consistency for both components was assessed using Crobach's Alpha values (Component $1 \alpha=0.959$, Component 2 $\alpha=0.920$ ). Component 1 reflects the combined risk factors, while Component 2 reflects the combined product-related drivers (i.e. the hybrid car is perceived as attractive, superior, and advantageous). Hence, the components were labelled as 'Risk' and 'Driver' respectively. Standardised scores were obtained using the Anderson-Rubin method (Field, 2013), which were then subjected to a two-step cluster analysis based on the Log-likelihood distance measure and the Akaike's Information Criterion (AIC) (Burnham \& Anderson, 2002). The results support a four-cluster solution with an average Silhouette measure of 0.5 (de Amorim \& Hennig, 2015). We identified the four clusters respectively as follows: Pessimists ( $\mathrm{n}=291$; high risk, low driver), Realists ( $\mathrm{n}=115$; high risk, high driver), Optimists ( $n=201$; low risk, high driver), and Casualists ( $n=210$; low risk, low driver).

A scatter plot is provided in Figure 1 showing the distribution of respondents across the four segments/clusters. Overall descriptive statistics for clusters are provided in Table 4, and descriptives for individual risk factors and product related drivers are provided in Table 5. Subsequent ANOVA tests for Risk $\left(F=621.7, p=0.000\right.$, adjusted partial $\left.\eta^{2}=0.695\right)$ and Driver $(F=379.6, p=0.000$, adjusted partial $\eta^{2}=0.582$ ) components between the clusters revealed significant differences, which are illustrated in Figure 2. Differences were interpreted further using Games-Howell post hoc tests at 95\% confidence interval. In order to further describe clusters, we tested for significant differences in terms of geographic (i.e. country), demographic (i.e. Age, Gender, Education, and Income), personal characteristics of respondents (Self-Image, and Values), and their purchase intention; these results are discussed in the following sections. 
Table 3: Results of the Principal Component Analysis (PCA)

\begin{tabular}{l|r|r}
\hline \multirow{2}{*}{\multicolumn{1}{c|}{ Variable }} & \multicolumn{2}{c}{ Component } \\
\cline { 2 - 3 } & 1 (Risk) & 2 (Driver) \\
\hline Psychological Risk (PSYRSK) & 0.93 & \\
\hline Network Externality Risk (NRSK) & 0.876 & \\
\hline Social Risk (SRSK) & 0.864 & \\
\hline Time Risk (TRSK) & 0.823 & \\
\hline Financial Risk (FRSK) & 0.771 & \\
\hline Product Advantage (PADV) & & 0.974 \\
\hline Product Attractiveness (PATTR) & & 0.941 \\
\hline Product Superiority (PSUP) & & 0.928 \\
\hline
\end{tabular}

Figure 1: Scatter plot of cases by cluster

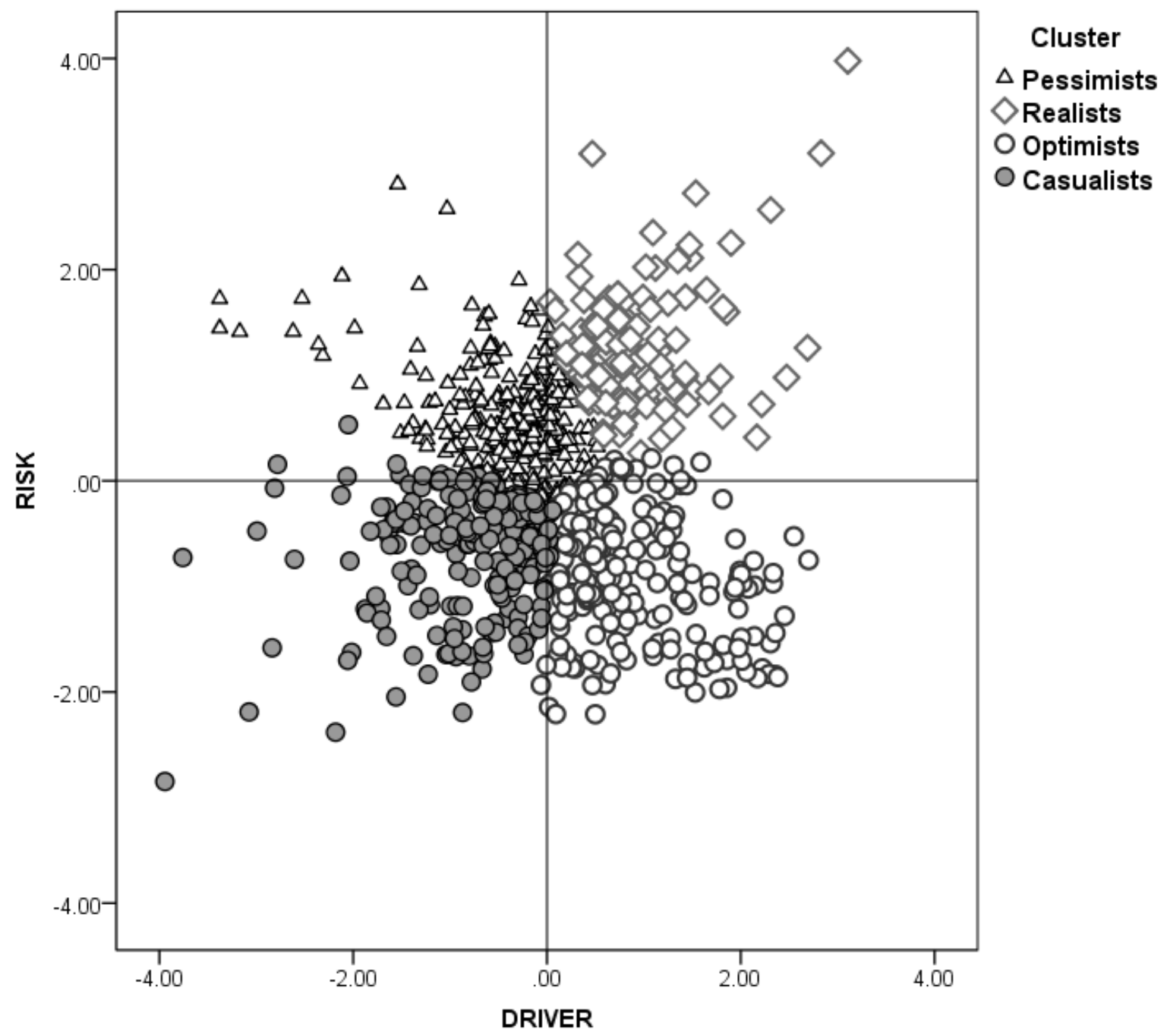


Figure 2: Differences in Risk and Driver components between segments/clusters

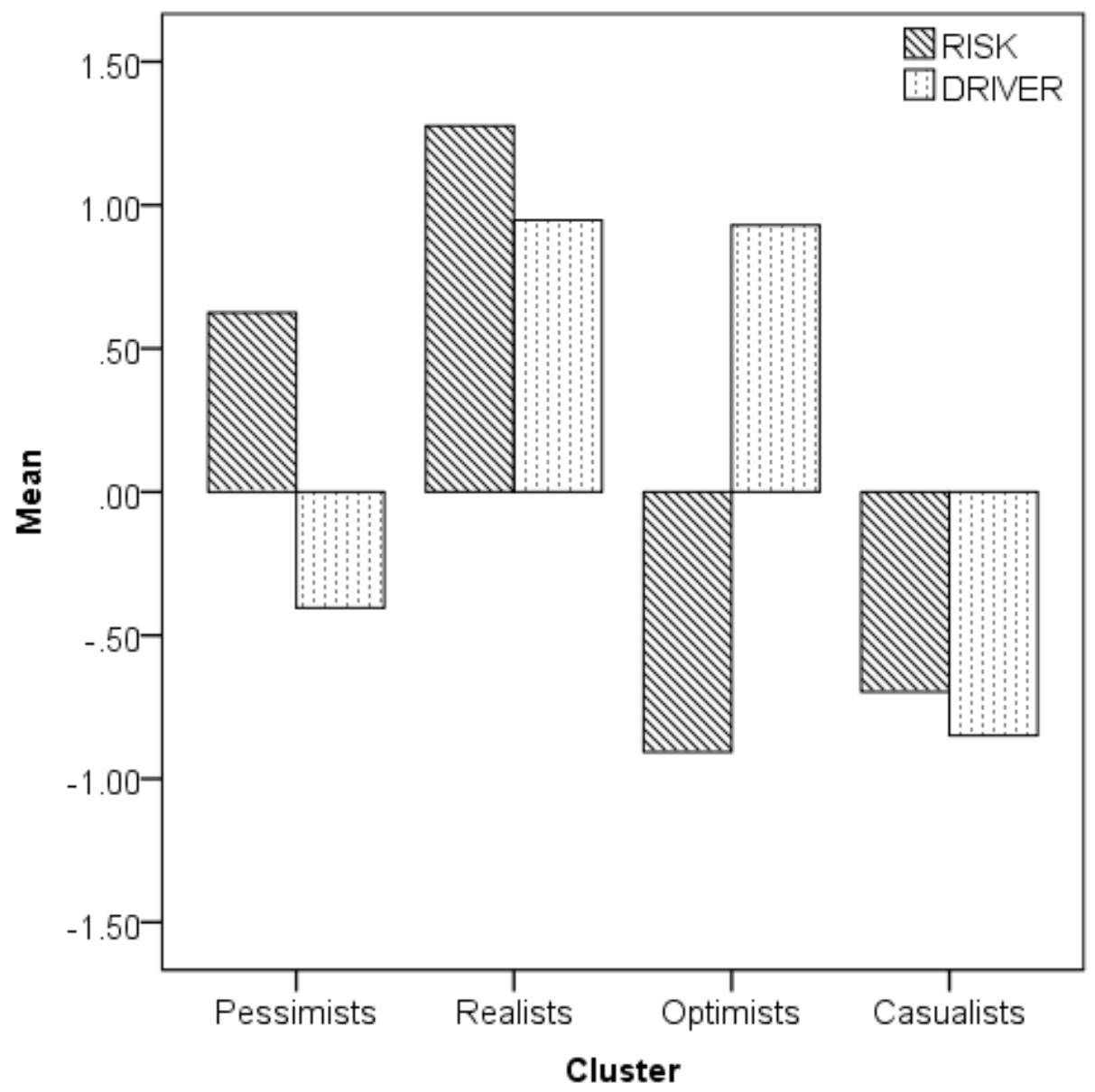

Table 4: Descriptive Statistics for segments/clusters

\begin{tabular}{c|c|r|r|r|r}
\hline \multirow{2}{*}{ Segment/Cluster } & \multirow{2}{*}{$\mathrm{n}$} & \multicolumn{2}{|c|}{ RISK } & \multicolumn{2}{c}{ DRIVER } \\
& & Mean & \multicolumn{1}{c}{ Std. Dev } & Mean & \multicolumn{1}{c}{ Std. Dev } \\
\hline Pessimists & 291 & 0.625 & 0.458 & -0.404 & 0.600 \\
Realists & 115 & 1.276 & 0.608 & 0.947 & 0.586 \\
Optimists & 201 & -0.907 & 0.619 & 0.930 & 0.674 \\
Casualists & 210 & -0.697 & 0.571 & -0.850 & 0.711 \\
\hline
\end{tabular}


Table 5: Descriptive statistics for clusters across individual risk and driver factors

\begin{tabular}{c|l|r|r|r|r|r|r|r|r}
\hline Cluster & Statistics & PSYRSK & FRSK & TRSK & SRSK & NRSK & PSUP & PATTR & PADV \\
\hline \multirow{2}{*}{$\begin{array}{c}\text { Pessimists } \\
(\mathrm{n}=291)\end{array}$} & Mean & 3.769 & 3.428 & 0.569 & 3.182 & 4.054 & 4.383 & 3.007 & 3.906 \\
\cline { 2 - 10 } & Std. Dev & 0.712 & 0.717 & 0.688 & 0.579 & 0.708 & 0.641 & 0.543 & 0.619 \\
\hline \multirow{2}{*}{$\begin{array}{c}\text { Realists } \\
(\mathrm{n}=115)\end{array}$} & Mean & 4.257 & 3.486 & 0.940 & 3.796 & 4.277 & 5.534 & 3.969 & 5.101 \\
\cline { 2 - 10 } & Std. Dev & 0.870 & 0.653 & 0.865 & 0.781 & 0.739 & 0.607 & 0.525 & 0.565 \\
\hline \multirow{2}{*}{$\begin{array}{c}\text { Optimists } \\
(\mathrm{n}=201)\end{array}$} & Mean & 1.806 & 1.672 & -0.844 & 1.935 & 2.065 & 5.732 & 4.358 & 5.337 \\
\cline { 2 - 10 } & Std. Dev & 0.721 & 0.888 & 0.715 & 0.666 & 0.889 & 0.681 & 0.602 & 0.683 \\
\hline \multirow{2}{*}{$\begin{array}{c}\text { Casualists } \\
(\mathrm{n}=210)\end{array}$} & Mean & 2.260 & 2.671 & -0.496 & 2.017 & 2.861 & 4.105 & 2.931 & 3.658 \\
\cline { 2 - 10 } & Std. Dev & 0.790 & 0.837 & 0.695 & 0.638 & 0.799 & 0.771 & 0.603 & 0.674 \\
\hline
\end{tabular}

\subsection{Country differences}

Pearson $\mathrm{X}^{2}$ test for independence showed that South Korean and Japanese respondents differed significantly between the clusters $(p=0.000 ; V=0.194, d f *=2)$. Post hoc test with Bonferroni corrections revealed that responses from South Korean respondents are more likely to be in the Pessimists cluster, followed by the Realists cluster, and least of all in either the Optimists or Casualists clusters. Japanese respondents are most likely to be in the Casualists cluster, followed by the Pessimists cluster, and least of all in the Realists cluster. Australians did not differ significantly between any of the four clusters (Pessimists, Realists, Optimists, and Casualists).

\subsection{Demographic differences}

Based on $X^{2}$ test results, clusters did not differ significantly by Age, Gender, or Income ( $\left.p>0.5\right)$. However, significant differences were observed among clusters for Education $(p=0.025 ; V=0.088$, $d f^{*}=3$ ) in the 'Postgraduate Degree' category. Post hoc test with Bonferroni corrections revealed that postgraduate degree holders are more likely to be Optimists than Casualists.

\subsection{Differences in personal characteristics}

We examined personal characteristics based on respondents' environmental SIMG, and five types of value-dimensions according to the classification by Hofstede: MAS, UA, LTO, IND, and PDI. Relevant descriptive statistics are summarised in Table 6. One-way ANOVA results indicated significant differences $(p=0.000, d f=3)$ between clusters for all of the variables examined: SIMG $(F=74.563$, 
$\left.\eta^{2}=0.219\right)$, MAS $\left(F=18.341, \eta^{2}=0.068\right)$, UA $\left(F=24.148, \eta^{2}=0.082\right)$, LTO $\left(F=29.033, \eta^{2}=0.100\right)$, IND $\left(F=20.018, \eta^{2}=0.075\right)$, and PDI $\left(F=21.449, \eta^{2}=0.087\right)$.

Post hoc tests at 95\% confidence level revealed that Realists recorded the highest level of SIMG, followed by Optimists, as opposed to Casualists with the least level of SIMG.

In terms of value-dimensions, Realists have the highest MAS, followed by Pessimists, but Casualists have the lowest level of MAS. However, Optimists have the highest level of UA, followed by Realists, whilst Casualists have the least level of UA. As for LTO, Realists have the most, followed by Optimists, but Casualists had the least. As for IND, Realists were the most collectivistic, followed by Optimists, whereas Casualists were the most individualistic. Finally, for PDI, Realists were again the highest, but Pessimists were second highest, whilst Casualists scored the least. 
Table 6: Descriptive statistics for personal characteristics

\begin{tabular}{|c|c|c|c|}
\hline Variable & Segment/Cluster & Mean & Std. Dev \\
\hline \multirow[t]{5}{*}{ SIMG } & Pessimists & 2.821 & 1.223 \\
\hline & Realists & 4.107 & 1.189 \\
\hline & Optimists & 4.063 & 1.428 \\
\hline & Casualists & 2.530 & 1.294 \\
\hline & Total & 3.233 & 1.457 \\
\hline \multirow[t]{5}{*}{ MAS } & Pessimists & 3.862 & 0.901 \\
\hline & Realists & 4.383 & 1.152 \\
\hline & Optimists & 3.620 & 1.275 \\
\hline & Casualists & 3.480 & 1.053 \\
\hline & Total & 3.777 & 1.113 \\
\hline \multirow[t]{5}{*}{ UA } & Pessimists & 3.934 & 0.653 \\
\hline & Realists & 4.288 & 0.670 \\
\hline & Optimists & 4.311 & 0.747 \\
\hline & Casualists & 3.782 & 0.734 \\
\hline & Total & 4.037 & 0.733 \\
\hline \multirow[t]{5}{*}{ LTO } & Pessimists & 3.900 & 0.649 \\
\hline & Realists & 4.410 & 0.708 \\
\hline & Optimists & 4.301 & 0.842 \\
\hline & Casualists & 3.758 & 0.783 \\
\hline & Total & 4.034 & 0.783 \\
\hline \multirow[t]{5}{*}{ IDV } & Pessimists & 3.749 & 0.789 \\
\hline & Realists & 4.292 & 0.952 \\
\hline & Optimists & 3.916 & 1.017 \\
\hline & Casualists & 3.453 & 0.995 \\
\hline & Total & 3.790 & 0.961 \\
\hline \multirow[t]{5}{*}{ PDI } & Pessimists & 3.210 & 0.931 \\
\hline & Realists & 3.672 & 1.289 \\
\hline & Optimists & 2.808 & 1.078 \\
\hline & Casualists & 2.782 & 0.967 \\
\hline & Total & 3.066 & 1.077 \\
\hline
\end{tabular}

\subsection{Purchase intention}

Concerning respondents' Purchase Intention (PI), one-way ANOVA results indicated significant differences $\left(F=55.723, d f=3, p=0.000, \eta^{2}=0.165\right)$ between the segments/clusters (see Table 7). Post hoc test (95\% confidence level) show Realists to have the highest level of $\mathrm{PI}$, followed by the Optimists, whereas the Casualists demonstrate the least level of PI. A multiple regression analysis with PI as the dependent and Drivers and Risks as independent variables revealed that Drivers have 
a positive effect on $\mathrm{PI}(\beta=0.618 ; p=0.000)$, whilst Risks have a negative effect $(\beta=-0.135 ; p=0.000)$, with the overall model predicting $40 \%$ of the total variance in $\mathrm{PI}(\mathrm{R}=0.632)$.

Table 7: Descriptive statistics for Purchase Intention

\begin{tabular}{l|r|r}
\hline Segment/Cluster & \multicolumn{1}{|c|}{ Mean } & Std. Dev \\
\hline Pessimists & 1.981 & 0.993 \\
\hline Realists & 2.924 & 1.143 \\
\hline Optimists & 2.597 & 1.237 \\
\hline Casualists & 1.644 & 0.756 \\
\hline Total & 2.179 & 1.124 \\
\hline
\end{tabular}

\subsection{DISCUSSION}

The present paper supports previous research (e.g. Axsen et al., 2015; Graham-Rowe et al., 2012; Heidenreich et al., 2017; Sang \& Bekhet, 2015) by showing that consumers consider the risks associated with adopting hybrid cars in parallel with the factors that drive purchase intention. Hence, this research is generally in line with studies suggesting that not only drivers, but particularly barriers of sustainable consumption need to be determined (e.g. Doorn \& Verhoef, 2015; Hüttel et al., 2018). To encourage the adoption of eco-friendly vehicles it is important for manufacturers to eliminate or reduce risk while simultaneously strengthening the factors that drive purchase intentions through product development, continued innovation and the development of targeted integrated marketing communications programs. As the segments with the highest purchase intention are characterized by high drivers, it is important for marketing communications efforts to focus on hybrid cars relative product: superiority; attractiveness; and advantages; and by doing so, encourage more consumers to join the realist and optimist segments.

The results corroborate previous research in that hybrid cars are attractive to consumers who identify themselves as environmentally-friendly individuals (e.g. Barbarossa et al., 2015; Ozaki \& Sevastyanova, 2011). However, the present study further demonstrates that an environmental selfimage is also associated with more perceived benefits of hybrid cars, which may in turn explain the increased likelihood of hybrid car adoption by consumers with a high environmental self-image. 
Moreover, this study underlines that consumers' interest in hybrid cars also depends on cultural dimensions.

Pessimists have some similarities with the 'uninspired' segment of consumers identified by Anable et al. (2016) and the 'laggards' described by Brand et al. (2017) in previous studies of hybrid and electric car adoption. However, as most previous scholars have not explicitly focused on risk, the other 3 segments appear to be unique to this research. In line with previous research (e.g. Kim \& Choi, 2005; Luchs et al., 2010; Urien \& Kilbourne, 2011), segments with high drivers (i.e. realists and optimists) are characterised by long term orientation, femininity, and collectivism which suggests that these cultural dimensions are determinants of environmentally-friendly consumer behaviour. Surprisingly, consumers in these segments also show a strong uncertainty avoidance. Uncertainty avoidance explains variations in the adoption of innovation, as high uncertainty avoidance is usually accompanied by a slower innovation adoption (Mooij \& Hofstede, 2010). Thus, the reasons for realists and optimists' potential slowness in innovation adoption need closer attention. Despite scoring high on drivers, realists and optimists may be hesitant to buy hybrid cars because they are less open to change/innovation. Marketing communications messages targeting realists should attempt to reduce perceived psychological risk and time risk which are high for consumers in this segment. Furthermore, minimisation of cognitive dissonance needs to be prioritised to assure realists and optimists understand that they are making the right choice when opting for a hybrid car. For example, the provision of detailed and third-party-certified product information may reduce cognitive dissonance.

Contrary to previous studies, our results do not indicate that hybrid car adopters significantly differ in their socio-demographic characteristics (Erdem et al., 2010; Hackbarth \& Madlener, 2013; Sang \& Bekhet, 2015). The only significant characteristic is education, as individuals with higher educational degrees are more likely to be members of a segments, which understands the many advantages of adopting hybrid cars. This is consistent with previous studies characterising hybrid car adopters (Erdem et al., 2010; Hackbarth \& Madlener, 2013; Sang \& Bekhet, 2015), and eco-friendly consumers 
in general (e.g. Doorn \& Verhoef, 2015; Hawcroft \& Milfont, 2010). Nevertheless, previous studies also point to conflicting results in profiling eco-friendly consumers based on socio-demographics. For example, the results of research conducted by other scholars have suggested that income can have a positive, negative, or insignificant effect on eco-friendly consumption (e.g. Cai \& Aguilar, 2013). Our results further question the suitability of socio-demographics in profiling hybrid car adopters and eco-friendly consumers in general. Given that socio-demographics also show low explanatory power in explaining eco-friendly consumption (Diamantopoulos et al., 2003), future work should primarily rely on other individual characteristics, which may better explain HEV adoption, such as self-image or value orientations.

\subsection{CONCLUSION AND IMPLICATIONS}

One of the most effective approaches to encouraging the adoption of more eco-friendly vehicles involves reducing the perceived risks that decrease purchase intentions through a combination of new product development, marketing communication and policy interventions. However, to make such initiatives successful, a better understanding of both the risks and drivers of eco-friendly car purchases is necessary. In the paper, we address gaps in the literature by analysing 5 types of risk and 3 drivers of HEV adoption. We identify four segments or clusters of consumers (Pessimists, Realists, Optimists and Casualists) and highlight the role that cultural values can play in influencing purchasing decisions in Australia, South Korea and Japan.

Whilst extant literature has often focused on either the drivers of environmentally friendly purchase decisions (e.g., Axsen et al., 2015; Barbarossa et al., 2015; Heidenreich et al., 2017), or the risk perceptions that hinder them (e.g. Hohl and Gaskell, 2008; Stone \& Grønhaug, 1993), our study highlights the importance of taking a more holistic viewpoint in relation to hybrid car purchase decisions. When drivers and risks are considered together, our findings show that there are global similarities and differences in terms of purchase decisions that transcend cultural and as geodemographic differences. For example, postgraduate degree holders in any of the three countries 
we sampled are most likely to be Optimists as opposed to Casualists. These and other findings of our study have implications for eco-friendly car manufacturers and policy makers, who are seeking to reduce greenhouse gases and pollution. For example, transnational policies such as the European Union's EU Emissions Trading System can be more effective across national borders not just for legal and economic reasons, but also because of cross-cultural changes in consumer attitudes that are more organic.

Our results support those of a small number of previous segmentation studies (e.g. Anable et al., 2016; Brand et al., 2017) and suggest that focussed strategic targeted policy interventions will be effective at encouraging the adoption of more eco-friendly cars. In line with other studies (e.g. Yang et al., 2017) our results suggest that as vehicle uptake remains low, continued government support and funding is necessary for programs that stimulate innovation, drive technological developments that stimulate product related improvements and reduce perceived risks (e.g. by enhancing battery storage and longevity). In addition, informational campaigns and other forms of education should continue to be developed, that enhance consumers awareness and stimulate adoption (Pierre et al., 2011). Purchase intentions were relatively low for consumers in all clusters. However, as the prominence of risk characteristics and product related drivers varies significantly between clusters, it is important to highlight the importance of educational campaigns, particularly targeting Optimists, who are likely to be early adopters due to presence of high drivers and low risk perceptions. The results of previous research have suggested that early adopters stimulate market growth in the ecofriendly car market (e.g. Anable et al., 2016; Axsen et al., 2015).

With regard to targeted interventions, Realists understand the factors that drive purchase intentions, however, they are concerned about the risks (particularly time risk). Providing Realists with clear information of car attributes and performance (Shukor et al., 2015), which simultaneously increases their knowledge (Adnan et al., 2017; Pierre et al., 2011), would decrease time risk and increase their purchase intention. Pessimists are the largest cluster and understand the benefits of 
HEV's, but are concerned about the risks. As network externality risks are a particular concern for pessimists, they would be unlikely to adopt hybrid cars before other consumers in their segment and are likely to be laggards. Casualists are influenced by a wider range of risks and drivers. Therefore, innovations that drive purchase intentions or reduce perceived risk in the future, may be needed to influence impending purchasing behaviour.

The focus of this paper has been on HEVs which may be more practical to adopt than PEVs (Wang et al., 2016) and as such may be a stepping stone as we move towards a totally PEV-based infrastructure later this century. Furthermore, the present study shows that the acceptance of HEVs differs between countries, and that cultural characteristics need to be considered when promoting HEVs, and when addressing consumers' perceived risks. Our findings also indicate that marketing communications strategies need to rely on a more targeted approach in order to increase consumers' purchase intention worldwide. Similarly, future studies about risks and drivers of ecofriendly consumption should consider the cultural context more specifically, and attempt to provide further insights into the cultural dependencies of previous findings.

Despite these insights, our study has the following limitations. As we relied on self-reported data, social responsibility bias (see: Sullamn et al., 2017), or the behaviour intention gap (Vermeir \& Verbeke, 2006) may have influenced the results. A further study using actual purchasing data would help researchers to better understand the factors that influence actual consumption by early adopters, but fail to identify other clusters or segments that may drive adoption in the future. We focussed on 3 countries (Australia, South Korea and Japan) and therefore our results may not be generalizable to other countries such as the USA, Germany, or in particular developing countries. Additional research that focuses on new countries would be useful. A longitudinal study that identifies how consumers move from segment to segment over time and/or identifies the impact further interventions by policy makers (e.g. reduced taxes or subsidies for electric fuel) or marketing communications campaigns could also provide additional insights. Further research that provides a better understanding of consumer perceptions of the risks and drivers associated with new 
environmentally friendly innovations such as autonomous electric vehicles that could be shared by communities of consumers with an interest in such innovations, would be helpful. Finally, a better understanding of other actors in the sustainability transition arena for eco-friendly cars, including those that influence organizational, institutional, political, economic, and socio-cultural dimensions would add new insights (Markard et al., 2012; Falcone, 2014).

\section{REFERENCES}

Adnan, N., Nordin, S. M., Rahman, I., Vasant, P. M., \& Noor, A. (2017). A comprehensive review on theoretical framework-based electric vehicle consumer adoption research. International Journal of Energy Research, 41(3), 317-335.

Al-Alawi, B.M., \& Bradley, T.H. (2013). Total cost of ownership, payback and consumer preference modelling of plug-in hybrid electric vehicles. Applied Energy, 103, 488-506.

Anable, J., Kinnear, N., Hutchins, R., Delmonte, E., \& Skippon, S. (2016). Consumer segmentation and demographic patterns (1910377511).

Axsen, J., Bailey, J., \& Castro, M. A. (2015). Preference and lifestyle heterogeneity among potential plug-in electric vehicle buyers. Energy Economics, 50, 190-201.

Axsen, J., \& Kurani, K. S. (2013). Hybrid, plug-in hybrid, or electric-What do car buyers want?. Energy Policy, 61, 532-543.

Ayadi, N., \& Lapeyre, A. (2016). Consumer purchase intentions for green products: Mediating role of WTP and moderating effect of framing. Journal of Marketing Communications, 22(4), 367384.

Bakar, N., \& Hasan-Basri, B. (2017). Strategic Innovation and Consumer Preferences: An Analysis of Malaysian Car Policy. Millineal Asia, 8(1), 64-77.

Barbarossa, C., Beckmann, S. C., De Pelsmacker, P., Moons, I., \& Gwozdz, W. (2015). A self-identity based model of electric car adoption intention: A cross-cultural comparative study. Journal of Environmental Psychology, 42, 149-160.

Boyd, T.C., \& Mason, C.H. (1999). The link between attractiveness of "extrabrand" attributes and the adoption of innovations. Journal of the Academy of Marketing Science, 27, 306-319.

Brand, C., Cluzel, C., \& Anable, J. (2017). Modeling the uptake of plug-in vehicles in a heterogeneous car market using a consumer segmentation approach. Transportation Research Part A: Policy and Practice, 97, 121-136.

Burnham, K.P., \& Anderson, D.R. (2002). Model Selection and Multimodel Inference: A Practical Information-Theoretic Approach (2nd ed.). New York: Springer-Verlag.

Cai, Z., \& Aguilar, F.X. (2013). Meta-analysis of consumer's willingness-to-pay premiums for certified wood products. Journal of Forest Economics, 1, 15-31. 
Carley, S., Krause, R.M., Lane, B.W., \& Graham, J.D. (2013). Intent to purchase a plug-in electric vehicle: A survey of early impressions in large US cites. Transportation Research Part D, 18, 39-45.

Cherubini, S., Iasevoli, G., \& Michelini, L. (2015). Product-service systems in the electric car industry: critical success factors in marketing. Journal of Cleaner Production, 97, 40-49.

de Amorim, R.C., \& Hennig, C. (2015). Recovering the number of clusters in data sets with noise features using feature rescaling factors. Information Sciences, 324, 126-145.

Dholakia, U.M. (2001). A motivational process model of product involvement and consumer risk perception. European Journal of Marketing, 35(11/12), 1340-1362.

Diamantopoulos, A., Schlegelmilch, B.B., Sinkovics, R.R., \& Bohlen, G.M. (2003). Can sociodemographics still play a role in profiling green consumers? A review of the evidence and an empirical investigation. Journal of Business Research, 56, 465-480.

Dong, J., Liu, C., \& Lin, Z. (2014). Charging Infrastructure Planning for Promoting Battery Electric Vehicles: An Activity-Based Approach Using Multiday Travel Data. Transportation Research C, 38, 44-55.

Doorn, J.v., \& Verhoef, P.C. (2015). Drivers of and barriers to organic purchase behavior. Journal of Retailing, 91(3), 436-450.

Dorn, A.v. (2017). Diesel and petrol cars to be banned by 2040, The Lancest (forthcoming)

Dowling, J. (2017). Is the electric car 'boom' over before it began? Australians shun electric cars, prefer hybrids instead. Herald Sun.

Dwyer, S., Mesak, H., \& Hsu, M. (2005). An exploratory examination of the influence of national culture on cross-national product diffusion. Journal of International Marketing, 13, 1-27.

Erdem, C., Sentuerk, I., \& Simsek, T. (2010). Identifying the factors affecting the willingness to pay for fuel-efficient vehicles in Turkey: A case of hybrids. Energy Policy, 38, 3038-3043.

Falcone, P. (2014). Sustainability Transitions: A Survey of an Emerging Field of Research. Environmental Management and Sustainable Development, 3(2), 61-83.

Field, A. (2013). Discovering Statistics Using IBM SPSS (4th ed.). London: Sage.

Forsythe, S., Liu, C., Shannon, D., \& Gardner, L. (2006). Development of a scale to measure the perceived benefits and risks of online shopping. Journal of Interactive Marketing, 20(2), 5575.

Gallagher, K.S., \& Muehlegger, E. (2011). Giving green to get green? Incentives and consumer adoption of hybrid vehicle technology. Journal of Environmental Economics and Management, 61(1), 1-15.

Graham-Rowe, E., Gardner, B., Abraham, C., Skippon, S., Dittmar, H., Hutchins, R., \& Stannard, J. (2012). Mainstream consumers driving plug-in battery-electric and plug-in hybrid electric cars: A qualitative analysis of responses and evaluations. Transportation Research Part A, 46, 140-153. 
Hackbarth, A., \& Madlener, R. (2013). Consumer preferences for alternative fuel vehicles: A discrete choice analysis. Transportation Research Part D, 25, 5-17.

Hawcroft, L.J., \& Milfont, T.L. (2010). The use (and abuse) of the new Environmental Paradigm Scale over the last 30 years: A meta-analysis. Journal of Environmental Psychology, 30(2), 143-158.

He, H., Fan, J., Li, Y., \& Li, J. (2017). When to switch to a hybrid electric vehicle: A replacement optimisation decision. Journal of Cleaner Production, 148, 295-303.

Heutel, G., \& Muehlegger, E. (2015). Consumer learning and hybrid vehicle adoption. Environmental Resource Economics, 62, 125-161

Heidenreich, S., Spieth, P., \& Petschnig, M. (2017). Ready, Steady, Green: Examining the Effectiveness of External Policies to Enhance the Adoption of Eco-Friendly Innovations. Journal of Product Innovation Management, 34 (3), 343-359.

Hofstede, G. (2001). Culture's consequences: Comparing values, behaviors, institutions and organizations across nations. Thousand Oaks: Sage Publications.

Hirunyawipada, T., \& Paswan, A.K. (2006). Consumer innovativeness and perceived risk: implications for high technology product adoption. Journal of Consumer Marketing, 23(4), 182-198.

Hohl, K., \& Gaskell, G. (2008). European Public Perceptions of Food Risk: Cross-National and Methodological Comparisons. Risk Analysis, 28(2), 311-324.

Hüttel, A., Ziesemer, F., Peyer, M., \& Balderjahn, I. (2018). To purchase or not? Why consumers make economiccaly (non-) sustainable consumption choices. Journal of Cleaner Production, $174,827-836$.

Hur, W.-M., Kim, Y., \& Park, K. (2013). Assessing the effects of perceived value and satisfaction on customer loyalty: A 'green' perspective. Corporate Social Responsibility and Environmental Management, 20, 146-156.

Iwata, K., \& Matsumoto, S. (2016). Use of hybrid vehicles in Japan: An analysis of used car market data. Transportation Research Part D: Transport and Environment, 46, 200-206.

Jansson, J., Marell, A., \& Nordlund, A. (2011). Exploring consumer adoption of a high involvement eco-innovation using value-belief-norm theory. Journal of Consumer Behaviour, 10(1), 51-60.

Jansson, J., Nordlund, A., \& Westin, K. (2017). Examining drivers of sustainable consumption: The influence of norms and opinion leadership on electric vehicle adoption in Sweden. Journal of Cleaner Production, 154, 176-187.

Jun, S.P. (2012). A comparative study of hype cycles among actors within the socio-technical system: With a focus on the case study of hybrid cars.Technological Forecasting and Social Change, 79(8), 1413-1430.

Kaptan, G., Shiloh, S., \& Onkal, D. (2013). Values and Risk Perceptions: A Cross-Cultural Examination. Risk Analysis, 33(2) 318-332.

Kim, D.J., Yim, M.-S., Sugumaran, V., \& Rao, H.R. (2016). Web assurance seal services, trust and consumers' concerns: an investigation of e-commerce transaction intentions across two nations. European Journal of Information Systems, 25(3), 252-273. 
Kim, Y., \& Choi, S.M. (2005). Antecedents of green purchase behaviour: An examination of collectivism, environmental concern and PCE. Advances in Consumer Research, 32, 11541176.

Laukkanen, T., Sinkkonen, S., \& Laukkanen, P. (2009). Communication strategies to overcome functional and psychological resistance to Internet banking. International Journal of Information Management, 29(2), 111-118.

Lee, Y., \& O'Connor, G.C. (2003). The impact of communication strategy on launching new products: The moderating role of product innovativeness. Journal of Product Innovation Management, 20, 4-21.

Luchs, M.G., Naylor, R.W., Irwin, J.R., \& Raghunathan, R. (2010). The sustainability liability: Potential negative effects of ethicality on product preference. Journal of Marketing, 74, 18-31.

Markard, J., Raven, R., \& Tuffer, B. (2012). Sustainability transitions: An emerging field of research and its prospects. Research Policy, 41(6), 955-967.

McGuire, K.A., Kimes, S.E., Lynn, M., Pullman, M.E., \& Lloyd, R.C. (2010). A framework for evaluating the customer wait experience. Journal of Service Management, 21(3), 269-290.

Meuter, M.L., Bitner, M J., Ostrom, A.L., \& Brown, S.W. (2005). Choosing among alternative service delivery modes: An investigation of customer trial of self-service technologies. Journal of Marketing, 69(2), 61-83.

Mooij, M.de, \& Hofstede, G. (2010). The Hofstede model. Applications to global branding and advertising strategy and research. International Journal of Advertising, 29 (1), 85-110.

Moons, I., \& De Pelsmacker, P. (2012). Emotions as determinants of electric car usage intention. Journal of Marketing Management, 28(3-4), 195-237.

Mortimer, G., Neale, L., Hasan, S.F.E., \& Dunphy, B. (2015). Investigating the factors influencing the adoption of m-banking: a cross cultural study. International Journal of Bank Marketing, 33(4), 545-570.

Morton, C., Anable, J., \& Nelson, J.D. (2016). Assessing the importance of car meanings and attitudes in consumer evaluations of electric vehicles. Energy Efficiency, 9(2), 495-509.

Nakata, C., Im, S., Park, H., \& Ha, Y.-W. (2006). Antecedents and consequences of Korean and Japanese new product advantage. Journal of Business Research, 59, 28-36.

Oliver, J.D., \& Lee, S.H. (2010). Hybrid car purchase intentions: a cross cultural analysis. Journal of Consumer Marketing, 27(2), 96-103.

Oliver, J.D., \& Rosen, D.E. (2010). Applying the environmental propensity framework: A segmented approach to hybrid electric vehicle marketing strategies. Journal of Marketing Theory and Practice, 18(4), 377-393.

Osburg, V.-S., Appelhanz, S., Toporowski, W., \& Schumann, M. (2016). An empirical investigation of wood product information valued by young consumers. Journal of Cleaner Production, 110, 170-179. 
Ozaki, R., \& Sevastyanova, K. (2011). Going hybrid: An analysis of consumer purchase motivations. Energy Policy, 39(5), 2217-2227.

Pae, J.H., \& Hyun, J.S. (2002). The impact of technology advancement strategies on consumers' patronage decisions. Journal of Product Innovation Management, 19(5), 375-383.

Paladino, A \& Pandit, A. (2012). Competing on service and branding in the renewable electricity sector. Energy Policy, 45, 378-388.

Park, C., \& Jun, J.-K. (2003). A cross-cultural comparison of Internet buying behavior: Effects of Internet usage, perceived risks, and innovativeness. International Marketing Review, 20(5), 534-553.

Petschnig, M., Heidenreich, S., \& Spieth, P. (2014). Innovative alternatives take action-Investigating determinants of alternative fuel vehicle adoption. Transportation Research Part A: Policy and Practice, 61, 68-83.

Pierre, M., Jemelin, C., \& Louvet, N. (2011). Driving an electric vehicle. A sociological analysis on pioneer users. Energy Efficiency, 4(4), 511-522.

Read, D.L., Brown, R.F., Thorsteinsson, E.B., Morgan, M., \& Price, I. (2013). The theory of planned behaviour as a model for predicting public opposition to wind farm developments. Journal of Environmental Psychology, 36, 70-76.

Rogers, E. M. (2010). Diffusion of innovations. Simon and Schuster.

Roselius, T. (1971). Consumer Rankings of Risk Reduction Methods. Journal of Marketing, 35(1),5661.

Sang, Y.-N., \& Bekhet, H A. (2015). Modelling electric vehicle usage intentions: an empirical study in Malaysia. Journal of Cleaner Production, 92, 75-83.

Sangkapichai, M., \& Saphores, J.-D. (2009). Why are Californians interested in hybrid cars? Journal of Environmental Planning and Management, 52, 79-96.

Schuitema, G., Anable, J., Skippon, S., \& Kinnear, N. (2013). The role of instrumental, hedonic and symbolic attributes in the intention to adopt electric vehicles. Transportation Research Part A: Policy and Practice, 48, 39-49.

Sheldon, T., Desharzo, J., \& Carson, R. (2017). Electric and Plug-In-Hybrid Demand: Lessons for an Emerging Market. Economic Inquiry, 55(2), 695-713.

Shukor, M.S., Sulaiman, Z., Thoo, A., \& Zakuan, N. (2015). The effect of emotional versus rational appeal in advertising on Malaysian consumers' purchase intention of hybrid car. Journal of Engineering and Applied Sciences, 11 (24), 14106-14111.

Sirgy, J.M. (1986). Self-congruity. New York: Praeger.

Soon, W.L., Seng, W., Luen, W., \& Siang, J. (2013). Hybrid vehicle adoption: A conceptual study. Journal of Education and Vocational Research, 4(6), 165-168.

Smith, S., \& Paladino, A. (2010). Eating clean and green? Investigating consumer motivations towards the purchase of organic food. Australasian Marketing Journal, 2010, 18(2), 93-104. 
Spencer, J., Lilley, D., \& Porter, S. (2015). The opportunities that different cultural contexts create for sustainable design: a laundry care example. Journal of Cleaner Production, 107, 279-290.

Steg, L. (2005). Car use: lust and must. Instrumental, symbolic and affective motives for car use. Transportation Research Part A: Policy and Practice, 39(2), 147-162.

Stone, R.N., \& Grønhaug, K. (1993). Perceived Risk: Further Considerations for the Marketing Discipline. European Journal of Marketing, 27(3), 39-50.

Sullman, M., Stephens, A., \& Hill, T. (2017). Gender Roles and the Expression of Driving Anger Amoung Ukranian Drivers. Risk Analysis, 37(1) 52-65.

Sylvers, E., \& Stoll, J. (2017). U.K. Targets Gasoline, Diesel Cars --- Joining European push, country sees internal-combustion engines banned by 2040. Wall Street Journal, Eastern edition; New York, N.Y. 27 July.

Urien, B., \& Kilbourne, W. (2011). Generativity and self-enhancement values in eco-friendly behavioural intentions and environmentally responsible consumption behavior. Psychology \& Marketing, 28, 69-90.

Vermeir, I., \& Verbeke, W. (2006). Sustianable Food Consumption: Exploring the Consumer "Attitude-Behaviour Intention Gap". Journal of Agricultural and Evironmental Ethics, 19, 169194.

Vigre, H., Domingues, A.R.C.C., Pedersen, U.B., \& Hald, H. (2016). An Approach to Cluster EU Member States into Groups According to Pathways of Salmonella in the Farm to Consumption Chain for Pork Products. Risk Analysis, 36(3), 450-460.

Wang, S., Fan, J., Zhao, D., Yang, S., \& Fu, Y. (2016). Predicting consumers' intention to adopt hybrid electric vehicles: using an extended version of the theory of planned behavior model. Transportation, 43(1), 123-143.

Webb, T.L., Benn, Y., \& Chang, B.P.I. (2014). Antecedents and consequences of monitoring domestic electricity consumption. Journal of Environmental Psychology, 40, 228-238.

Weber, E.U., \& Hsee, C. (1998). Cross-cultural differences in risk perception, but cross-cultural similarities in attitudes towards perceived risk. Management Science, 44(9), 1205-1217.

Yang, X., Jin, W., Jiang, H., Shen., W., \& Han, W. (2017). Car ownership policies in China: Preferences of residents and influence on the choice of electric cars. Transport Policy, 58, 62-71. 


\section{Table captions}

Table 1: Overview of perceived risks and drivers of hybrid car adoption

Table 2: Summary of descriptive statistics

Table 3: Results of the Principal Component Analysis (PCA)

Table 4: Descriptive Statistics for segments/clusters

Table 5: Descriptive statistics for clusters across individual risk and driver factors

Table 6: Descriptive statistics for personal characteristics

Table 7: Descriptive statistics for Purchase Intention

\section{Figure captions}

Figure 1: Scatter plot of cases by cluster

Figure 2: Differences in Risk and Driver components between segments/clusters 